\title{
Natureza, infância e ciência no Brasil dos anos 1920/30: a pedagogia moderna e a Bibliotheca de educação
}

\author{
Marcelo Rito* \\ Julio Groppa Aquino**
}

\begin{abstract}
Resumo:
O presente artigo propõe-se a examinar a emergência daquilo que se convencionou denominar modernidade pedagógica no Brasil dos anos 1920/30, por meio de uma análise, de vocação genealógica, da racionalidade normativa então vigente, bem como de seus possíveis efeitos sobre a atualidade escolar. Coube-nos, assim, problematizar as investidas devotadas à vinculação determinista entre certas noções de natureza, de infância e de ciência. Tendo como fonte alguns volumes publicados junto à Bibliotheca de educação, importante veículo de difusão de ideias na fase áurea do escolanovismo, a investigação levada a cabo aponta, à luz de uma teorização de viés pós-estruturalista, que as práticas escolares modernas vêm-se firmando como vigorosas matrizes para a forja e o espraiamento de bioidentidades.
\end{abstract}

\section{Palavras-chave:}

modernidade pedagógica; infância; normalização; bioidentidades; coleção Bibliotheca de educação.

\footnotetext{
* Graduado em História pela Faculdade de Filosofia, Letras e Ciências Humanas da Universidade de São Paulo (USP). Doutorando em Educação pela Faculdade de Educação da Universidade de São Paulo (USP).

** Livre-docente da Faculdade de Educação da Universidade de São Paulo (USP).
} 


\title{
Nature, childhood and science in Brazil in the 1920's and 30's: modern pedagogy and the Bibliotheca de educação collection
}

\section{Marcelo Rito Julio Groppa Aquino}

\begin{abstract}
:
The purpose of this article was to study the emergence of what is conventionally called pedagogical modernity in Brazil in the 1920 's and 30's, through the genealogical analysis of the normative rationality in force at the time, along with their possible effects on contemporary education. Our aim was to discuss the efforts and attempts of this rationality devoted to the deterministic record linkage between certain notions about nature, childhood and science. Consulting some volumes published by the Bibliotheca de educação - an important means of disseminating ideas in the golden age of the New Education ("escolanovismo") - our investigation suggests that, considering a theorization of poststructuralist bias, modern school practices have become a strong foundation for the creation and spreading of bioidentities.
\end{abstract}

Keywords:

pedagogical modernity; childhood; normalization; bioidentities; Bibliotheca de educação collection. 
Nos discursos que marcaram a emergência da modernidade pedagógica brasileira, raramente a tríade natureza/infância/ciência esteve ausente do debate educacional. Ora objeto de crítica, ora ponto pacífico, a definição da criança como um ente formado por um substrato hereditário, portador de condutas previsíveis e de habilidades em desenvolvimento, remonta a quase um século, constituindo até hoje um rico cabedal das palavras e coisas educacionais.

Destarte, este trabalho ambiciona tratar de tal codificação histórica. Dito de outra maneira, visamos problematizar as diferentes formas pelas quais os profissionais da educação do início do século passado colocaram em palavras os comportamentos dos aprendizes, ou, mais especificamente, como os primeiros estabeleceram premissas norteadoras para a gestão dos corpos e almas dos segundos e, assim fazendo, findaram, no mesmo golpe, por fabular suas origens e decretar seus porvires.

Para tanto, tais profissionais dedicaram-se a medir, pesar, contar e comparar grandezas, racionalizando a linguagem por meio da qual descreviam os educandos sob avaliação. Nosso objeto de pesquisa - textos de divulgação científica publicados nas décadas de 1920 e 1930 por autores ligados à pedagogia escolanovista no Brasil - é mostra contundente de tal racionalização.

Do grande oceano composto por dizeres que circularam no universo escolar brasileiro no período aqui analisado, optamos por textos produzidos para a coleção Bibliotheca de educação, editada pela Companhia Melhoramentos entre os anos de 1927 e 1979, perfazendo o total de 36 volumes e tendo sua "fase áurea" entre seu lançamento e os três anos subsequentes (MONARCHA, 1997).

O destaque que concedemos à referida coleção pressupõe a eminência de seu editor. Lourenço Filho foi um importante reformista brasileiro que tem em seu currículo o mérito de ter introduzido no Brasil o primeiro laboratório de psicologia experimental. Também participou da reforma educacional do Ceará em 1922, foi docente de psicologia e pedagogia na Escola Normal de São Paulo em 1924, dirigiu a Revista de educação e figurou em vários cargos da administração varguista durante a década de 1930.

O prestígio intelectual e político de Lourenço Filho permitiu que ele reunisse uma consistente mostra da intelectualidade brasileira e internacional em torno da coleção Bibliotheca de educação. Os autores dos volumes, assim como os tradutores, foram escolhidos pelo editor em razão de seus vínculos com instituições estatais, imprimindo "[...] às obras um tom alto e oficial [...]" (MONARCHA, 1997, p. 40). 
Das nove obras escolhidas para exame neste artigo, sete são volumes da referida coleção publicados entre 1927 e 1929; a eles foram somadas outras duas referências em virtude de sua visível conexão temática com as primeiras.

Tomaremos primeiramente Psychologia experimental de Henri Piéron (1927), cujo interesse volta-se para a aplicação de um profícuo modelo científico para verificação das capacidades discentes. O mesmo enfoque de Piéron aparece na segunda obra de que tratamos: A escola e a psychologia experimental, de Edouard Claparède (1928). Segue-se a esta o volume assinado por Sampaio Doria (1928), sob o título Educação moral e educação econômica, cuja abordagem desloca-se para um inquérito sobre a origem da vontade nos educandos. Doria segue a linha de Durkheim, autor também presente no nosso cenário investigativo com o volume Educação e sociologia (1929). Depois da discussão sobre vontade e valores morais, voltamo-nos para aqueles autores que discorrem sobre o inatismo de certas tendências comportamentais. Desses autores, retomamos Peregrino Junior com seu livro Biotypologia e educação (1936), o qual não consta propriamente da Bibliotheca de educação, mas foi coligido em razão da grande quantidade de referências à sua descrição dos biotipos em diversos volumes da coleção. Em conexão direta com Peregrino Junior, encontramos o quarto volume da coleção: Temperamento e carácter sob o ponto de vista educativo, de Henrique Geenen (1929), cujo objetivo é o de dissertar sobre o binômio hereditário/adquirido na determinação acerca do que ele considera indivíduo humano. A herança biológica também está presente nas preocupações de Octavio Domingues, que comparece em nosso estudo com duas obras: $A$ hereditariedade em face da educação (1929), a qual compõe o sexto volume da Bibliotheca de educação, assim como Eugenia (1933), cujos enunciados figuram de modo bastante coerente com o discurso presente em grande parte da coleção. Analisamos ainda a obra A lei biogenética e a escola activa, de autoria de Adolphe Ferrière (1929), na qual aparecem ilustrativas considerações acerca do tema da liberdade, permitindo-nos sintetizar, a partir dele, a correlação intrínseca entre natureza (tendências hereditárias), ciência (pedagogia psicologizada) e criança (humano em desenvolvimento) presente na Bibliotheca de educação.

Por meio da investigação por nós levada a cabo, foi possível constatar que, desde os primórdios da escola reformada dos anos 1920, a observação criteriosa, a anotação persistente e a intervenção segura parecem ter estado sempre presentes no horizonte dos pesquisadores da psique infantil/discente. 
Assim, máquinas foram produzidas com o fito de apurar as coletas; gráficos, tabelas e quadros definiram as normas; a partir delas, teorizações minuciosas e previsões lógicas foram divulgadas.

Tal momento histórico, condizente com o avanço da concentração urbana no sudeste do país, é marcado por iniciativas voltadas para uma suposta cientificidade definitiva dos processos educativos. Daí os cruzamentos da psicologia experimental com a sociologia, a educação moral, a genética, a estatística, dentre outros saberes em voga; todos eles visando a garantir uma enunciação tão explicativa quanto preditiva dos diferentes comportamentos. Segundo José Gonçalves Gondra (2000, p. 105-106), tratava-se de um tempo em que a urbanidade burguesa projetava uma civilização higienizada, por meio da qual, "[...] tendo em vista gerar/produzir sujeitos que pudessem ser integrados positivamente ao mundo do trabalho [...]", o cuidado com a criança garantiria a "[...] defesa da sociedade [...]".

Parece-nos, ademais, que tais iniciativas operaram no sentido de constituir uma nova gramática para determinar a natureza humana. Desse modo, as narrativas de si e, notadamente, as explicações para o sucesso ou fracasso - fossem de natureza escolar, profissional ou social - eram submetidas a um circuito de definições que codificava as condutas e, ao mesmo tempo, as segmentava de acordo com um conjunto de atitudes esperadas. Os cientistas pedagógicos modernos, ao disporem de um montante de códigos em torno dos quais todos os humanos deveriam ser regulados, operaram vivamente em torno da sequência verificação-diagnóstico-prevenção, com vistas a definir as linhas de sustentação de uma educação escolar doravante moderna.

\section{Fisiologia, comportamento e identidades contemporâneas}

Desde o início do século XX, a fisiologia como núcleo gerador de narrativas identitárias e, portanto, objeto de múltiplas investigações acerca do comportamento social, tem-se apresentado de modo bastante recorrente, sobretudo para aqueles que se dedicaram a dissertar sobre problemas detectados na população de escolares.

No presente, há uma significativa circulação de textos que se valem de cânones do linguajar psiquiátrico a fim de discorrer sobre transtornos ou déficits orgânicos, particularmente cerebrais (por exemplo: BENCZIK, 
2000; MATTOS, 2001; ROHDE, 2003; SILVA, 2003). Tais escritos, em geral, tomam por referência avaliações estandardizadas para definir "[...] alterações neuroquímicas de origem provavelmente genética [...]” (ROHDE, 2003, p. 13). O critério basal para a enunciação de suas verdades assenta-se na sucessão de testes, avaliações e medições realizadas pela comunidade científica com o intuito de estabelecer, com crescente detalhamento estatístico, argumentos irrefutáveis para determinadas hipóteses acerca do funcionamento cerebral e seu suposto papel prevalente, seja nos mecanismos da cognição, seja nas relações interpessoais.

O substrato estatístico, o mapeamento cerebral, as hipóteses químicas e as considerações genéticas utilizadas pelos psiquiatras, incontinente, adentram o universo escolar. Nessa perspectiva, sacraliza-se uma definição de natureza humana segundo a qual o homem é um ser que possui, desde a infância, determinadas tendências internas, cujo desenvolvimento ocorreria a partir de certos condicionantes sociais. A vida como um processo de aperfeiçoamento contínuo e progressivo em direção a uma maturidade racional e autônoma, que aceita a si mesma e se ajusta ao meio em que vive, é, parece-nos, um dos pontos de chegada desse tipo de abordagem determinista do trabalho educacional. Tal perspectiva leva em conta que a educação de todos só pode ser alcançada na medida em que ela se dirige ao corpo de cada um dos indivíduos envolvidos.

Tal movimento de absorção das idiossincrasias por uma sequência de ações esperadas pelos cientistas não é atual. Consideramos que ele emerge no Brasil ao mesmo tempo em que a escola brasileira assume características massivas; época em que São Paulo, por exemplo, viveu os "[...] frementes anos vinte [...]" (SEVCENKO, 1992), caracterizados pelo afluxo populacional para as cidades em razão do surto industrial gerado pelo contexto da Primeira Guerra Mundial.

Observa-se igualmente que, já no final do século XIX, em diversos setores da gestão pública brasileira, elevam-se as preocupações quanto ao manejo dos grandes contingentes citadinos. A obra Da(n)ação da norma (MACHADO et al., 1978) é rica em narrativas acerca das preocupações da medicina social em relação à higiene urbana; por meio delas, torna-se evidente a conexão entre o corpo saudável do indivíduo e o corpo harmônico da cidade. Nesse contexto, a escola moderna, tal como analisada por Cecília Hanna Mate (2002), eleva-se como grande arauto de práticas racionais 
dirigidas à administração dos corpos dos escolares, no sentido de inseri-los em um dado contingente populacional.

Desta feita, a conexão entre fisiologia e comportamento parece-nos o pontochave para analisarmos o contínuo processo de racionalização das relações sociais e, particularmente, das escolares. Para alguns autores contemporâneos, tal conexão possui um potencial condutivo bastante refinado, uma vez que ela teria como alvo, precisamente, a constituição de bioidentidades.

Nikolas Rose possui uma extensa investigação sobre a questão. No texto intitulado Neurochemical selves, por exemplo, apresenta uma detalhada pesquisa sobre a ligação entre o uso de psicofármacos e a produção de subjetividades na contemporaneidade; pesquisa orientada pela indagação: “Como nos tornamos seres neuroquímicos?” (ROSE, 2003). Em suas análises, o autor inglês descreve a íntima vinculação entre a pesquisa científica, os interesses das companhias farmacêuticas e o processo de formulação médica dos transtornos psiquiátricos. $\mathrm{O}$ autor assevera que, em torno da hipótese serotonínica para determinados distúrbios mentais, a indústria farmacêutica pode, desde meados da década de 1950, contribuir para a formação de uma espécie de sociedade psicofarmacológica, no interior da qual a modificação de humor e de comportamento por meios químicos ter-se-ia tornado ação rotineira. Ao visualizarmos o uso corriqueiro de medicamentos, notadamente da Ritalina ${ }^{1}$, no cotidiano escolar atual (LIMA, 2005), comungamos com as suposições de Rose (2001) acerca da criação de novos critérios de sociabilidade e seus efeitos marcantes no meio social. Tais critérios baseiamse na exclusão do sofrimento íntimo e na busca da normalidade funcional do corpo, apontando, concomitantemente, para inusitadas ligações entre natureza, fisiologia cerebral e comportamento. Para Rose, a racionalidade terapêutica da psiquiatria insere o indivíduo numa determinada categoria patológica, para depois tratá-lo particularmente.

Contemporâneo a Rose, Paul Rabinow (2002, p. 143) estudou enunciados proferidos por cientistas envolvidos com a criação do Projeto Genoma Humano, tendo cunhado o termo biossociabilidade para nomear "[...] um tipo verdadeiramente novo de autoprodução [...]” forjado nas definições científicas que intercambiam fisiologia, comportamento e genética. Rabinow afirma que, no espraiamento das explicações genéticas, há um inequívoco

1 Nome comercial do Metilfenidato adotado pela Novartis biociências. 
processo de conversão da noção de prevenção em vigilância, apontando, via intervenção bioquímica, para "[...] comportamentos desviantes a serem minimizados, e de comportamentos saudáveis a serem maximizados [...]" (RABINOW, 2002, p. 145). Assim, os indivíduos, ao assumirem o lócus biológico a que pertencem, poderiam controlar suas relações sociais e, por conseguinte, se afastar de possíveis fatores degenerativos. A antiga medicina social seria recodificada, agora, em terapia para normais.

Também Robert Castel (1987, p. 18) demonstra que, no movimento da antipsiquiatria no segundo pós-guerra, o retorno do objetivismo médico demandou a modificação das tecnologias preventivas em direção à "[...] promoção de um trabalho psicológico sobre si mesmo [...]”. A atenção sobre si teria decretado "[...] novas competências do médico-psiquiatra fazendo-o intervir como conselheiro junto a instituições como escola, exército, empresa quando estas pretendem racionalizar recrutamento, seleção e organização interna que um expert pode resolver [...]" (ibidem, p. 70).

A companhia dos três autores acima faz-nos supor que o olhar médico, psíquico e genético sobre as populações mira, antes de tudo, os indivíduos. Estes, ao assumirem as identidades que lhes são oferecidas, passam a viver segundo os comandos ditados pelos especialistas, os quais incitam a inserção de cada qual em um tipo psicofísico investigável, tratável e, portanto, previsível. Entre tais especialistas, incluímos os pedagogos, pelo seu privilegiado papel na concepção das modernas concepções de infância.

Nesse sentido, estamos convencidos de que a interface entre fisiologia e comportamento é bastante fértil para problematizarmos os discursos que oferecem matrizes para identidades escolares, na medida em que reputamos - ao lado de Jorge Ramos do Ó (2009, p. 39) - a pedagogia como o campo da "[...] construção racional dos fatos da intimidade, tendo como objectivo o estabelecimento do mapa da alma humana [...]”. Nesse sentido, “[...] a alma seria portanto o produto diferenciado que a razão de Estado encomendaria à pedagogia psi [...]" (ibidem, p. 40).

A escola moderna, no momento em que sobreleva as definições biológicas para definir as individualidades de seus pupilos, oferece a eles critérios estritos de identitarização. Destarte, apresentamos como hipótese que tal modelo de escolarização, emergente no Brasil dos anos 1920, converte-se, antes de mais nada, em uma potente matriz de bioidentidades. 


\section{Aportes teórico-metodológicos da investigação}

O procedimento a balizar nosso enfrentamento com as fontes aproximanos daquele utilizado por Ramos do Ó (2009, p. 26), para quem “[...] estabelecer os processos de criação e circulação dos textos é, literalmente, estar a fazer história. A verdade de uma fonte documental encontra-se, portanto, nos objectivos para que foi escrita e nas modalidades em que se viu transacionada [...]".

A problematização dos jogos de verdade em torno do corpo infantil na modernidade educacional brasileira circunscreve nosso enfoque analítico, uma vez que pretendemos focalizar a "[...] história do que os homens chamaram de verdades e de suas lutas em torno dessas verdades [...]" (VEYNE, 1982, p. 172). Daí a opção por não procurar as causas anteriores de tais ou quais enquadres históricos, mas perseguir seus efeitos como desdobramentos de práticas específicas de poder. Tal como Ramos do Ó, atentaremos para as condições de produção e circulação dos discursos no intuito de visualizarmos a potência produtiva das enunciações quando elas tomam o outro como objeto de estudo e intervenção.

Para especular sobre os efeitos de poder gerados pelos enunciados a que nos dedicamos, propomo-nos a analisá-los à moda foucaultiana, ou seja, almejamos "[...] descrever os enunciados, grupos inteiros de enunciados fazendo surgir as relações de implicação, de oposição, de exclusão, que podem ligá-los novamente [...]" (FOUCAULT, 2000, p. 65-66).

Trata-se, portanto, de tomar os enunciados não como ilustrativos de um momento ou como reveladores de visões de mundo subjacentes aos fatos históricos, mas como substratos possíveis, do ponto de vista genealógico, para a constituição de determinados traços das subjetividades contemporâneas.

Nesse sentido, procuramos conjecturar nas fontes as práticas subjetivadoras que as suportam e que, ao mesmo tempo, são por elas alimentadas. Sem nenhuma pretensão elucidativa, ensejamos, no entanto, compor eixos temáticos a partir dos quais esperamos estabelecer algumas linhas de parentesco entre os diferentes critérios de enunciação empregados.

Consideramos que os discursos são práticas criadoras de “[...] efeito, efeito conhecido de antemão, regulado de antemão [...]” (FOUCAULT, 2010, p. 60); donde tal regulação evidenciar o caráter performativo de todo enunciado, cujas leis internas de produção delineiam esquemas subjetivadores. 
Acompanhamos, ainda, Paul Veyne ao afirmar que "[...] as verdades já são imaginações e que a imaginação está no poder desde sempre; ela e não a realidade, a razão ou o longo trabalho do negativo [...]" (FOUCAULT, 1984, p. 10).

Assim, os enunciados que analisaremos a seguir são situados precisamente no plano imaginativo, no sentido de que a " [...] imaginação constituinte não é um dom de invenção que residiria nos indivíduos; é uma espécie de espírito objetivo em torno do qual os indivíduos se socializam [...]" (VEYNE, 1984, p. 124).

Dessa maneira, para constituir algo como a história dos jogos de veridicção que envolveram a produção enunciativa em torno da criação da escola moderna no Brasil, não podemos fazer mais do que angariar discursos, alinhavar sua lógica interna, estabelecer as aproximações e distensões entre os diferentes interlocutores para, desse modo, vislumbrar o espírito objetivo de um tempo no qual se imaginaram alunos convivendo em escolas cujos cuidados desdobravam-se, primordialmente, como mantenedoras das condições da normalidade daqueles.

\section{A Bibliotheca de educação como fonte enunciativa}

A escola de massas no Brasil - instituída pela nova razão de Estado configurada com Vargas nos anos 1930 - começou a se tornar um problema desde a década anterior, fosse no sentido de racionalizar a educação nacional por meio da preocupação com o "[...] rendimento, eficiência, produtividade, objetividade, previsibilidade, medição estatística, controle [...]" (MATE, 2002, p. 22); ou de "[...] transformar as normas tradicionais da organização escolar [...]" (LOURENÇO FILHO, 1963, p. 15); ou "[...] curar o inconsciente do brasileiro [...]" (ARTUR RAMOS, 1939 apud PATTO, 1999, p.106); ou como "[...] requisito do desenvolvimento nacional [...]" (PATTO, 1984, p. 56); ou ainda como "[...] clínicas em que os males nacionais associados à mistura de raças poderiam ser curados [...]” (D’AVILA, 2006, p. 22). É incontestável que, a partir dos anos 1920, cresceu visivelmente o número de instituições estatais, publicações analíticas, dados estatísticos e lideranças políticas, todos conjugados no sentido de assegurar o espraiamento de uma educação 
pública tão normalizadora quanto cientificamente orientada. A Bibliotheca de educação é, sem dúvida, um mirante fecundo da época.

O processo de criação da coleção relaciona as obras contidas nela a um princípio comum: ela parece ter sido criada para instruir os professores no que tange às descobertas científicas de então e, por conseguinte, para iluminar as práticas pedagógicas.

A Companhia Melhoramentos orientou a distribuição e a comercialização da Bibliotheca, sobretudo, para professores em aperfeiçoamento e pais de alunos - o que se verifica quando atentamos para o didatismo dos textos, cujos capítulos são entrecortados por abundantes subtítulos, de modo a garantir a precisão e o encadeamento linear das definições. Estas são apresentadas como resultado final das pesquisas de seus autores, demonstrando incontestável compromisso com a formação técnico-pedagógica dos leitores.

Autores de passagem pelo Brasil, como Piéron, Binet, Claparède e Fauconnet, tiveram seus textos traduzidos e inseridos em diferentes volumes da coleção. Nessa época, segundo Carlos Monarcha (1997), ocorreu uma intensa produção de coleções voltadas para professores, normalistas e pais de alunos. A Companhia Editora Nacional, a Livraria José Olympio Editora e a Livraria Martins eram as principais editoras voltadas a esse nicho de mercado.

No caso da Bibliotheca de educação, as edições foram regulares; as reedições, frequentes e as tiragens, significativas: 3.000 exemplares em média. Entre 1927 e 1941, o total de exemplares publicados foi de 137.800 (MONARCHA, 1997). A maioria dos volumes foi utilizada em cursos de formação de professores, “[...] adquirindo a feição de manuais de ensino [...]" (ibidem, p. 35).

Na apresentação do primeiro volume, vemos anunciado que os tomos abordariam duas séries previamente definidas. A primeira delas seria dedicada a expor as "[...] bases scientificas do ensino, já do ponto de vista geneticofunccional da sua organisação, já do ponto de vista da finalidade social e moral a que deve tender a elevação do homem, como cidadão e como homem [...]" (PIÉRON, 1927, p. 4).

Na segunda série, “[...] serão examinados os meios praticos de educação e ensino, tratando-se de modo particular das aplicações que mais nos convenham, com indicações e crítica de systemas [...]" (ibidem, p. 5).

Ao apresentar os propósitos da coleção, o editor Lourenço Filho vê o aluno como um ser constituído sobre determinadas bases fisiológicas, de que a moralidade, advinda da socialização, seria parte integrante; além disso, 
esse indivíduo biológico-moral é considerado um ente em busca da plena realização de sua humanidade, tendo como função mater o exercício de seu papel de cidadão. Ou seja, oferece-se uma definição de vida em que o ser biológico e o ser social são personagens indistintos e constitutivos daquilo que se poderia denominar humano em geral.

Nesse percurso humanizador ou, conforme Maria Helena Patto (1999), civilizador, a educação é tomada como um espaço social em que despontam as anormalidades e, portanto, dela emanaria o manancial de termos que tornaria as concepções dizíveis e as intervenções factíveis no corpo biológico-moral do cidadão.

Ao analisarmos os enunciados referidos como uma rede de definições e, em última instância, de autodefinições de si, ansiamos criar uma trilha para deslindarmos alguns aspectos do funcionamento do complexo saber-poder instituído pela biologia, pela medicina, pela eugenia, pela psicologia, pela psicanálise e pela psiquiatria que circundaram a escola moderna.

Esmiucemos nosso objeto: as práticas discursivas orientadas para a definição e, por conseguinte, para o governo dos alunos tomados como crianças, e destas como seres biológicos em desenvolvimento.

Para tanto, tomamos como critérios analíticos determinados aspectos relacionados à definição de natureza humana e, no interior dela, o papel atribuído à criança. Também atentamos para os modos de formular tal natureza pelo expediente dos testes, medições, exames ou suposições filosóficas; sempre no sentido de relacionar os critérios verificatórios às pretensões generalizantes dos avaliadores. Auscultamos igualmente as relações que os autores operam entre uma natureza em geral e os comportamentos individuais. Por fim, destacamos, nos enunciados, propostas de intervenção prática condizentes com as suposições acerca da natureza, da infância e dos métodos científicos empregados.

\section{Pedagogia moderna: traços de uma natureza}

O primeiro volume da Bibliotheca de educação foi escrito por Henri Piéron (1927) e traduzido por Lourenço Filho. Fato evidente: o autor lança as bases a partir das quais a coleção trafegará. Em Psychologia experimental (PIÉRON, 1927), o objeto investigado é uma criança, antes disso, um 
estudante; antes, um filho, e antes de todos esses, um ser humano. A acuidade nas respostas, a conduta positiva, o procedimento respeitoso, a sofisticação artística e a competência na repetição eram as condutas esperadas dos avaliados. Estes deviam ser verificados quanto: à sensibilidade visual; à percepção, ora do espaço ora da verdade; ao reconhecimento da cinestesia e tato; à capacidade de reconhecer o tempo; à velocidade e precisão das reações; à motricidade e aos reflexos incondicionados; à força e forma de manifestar emoções; à atenção e ao esforço mental; à análise dos órgãos dos sentidos; à excitação, depressão e impacto provocados por choques emocionais; à reação psicogalvânica (relativa à corrente elétrica); à memória e aprendizagem; à fixação e esquecimento; às leis do hábito e precisão dos movimentos; aos processos associativos e pensamento; às reações automáticas e benefícios dos exercícios; à introspecção e medidas funcionais, tais como temperatura, amplitude respiratória e valor do metabolismo; às medidas morfológicas (peso, altura, envergadura etc.) com o fito de definir o grupo étnico; ao nível global de desenvolvimento da inteligência; às aptidões espaciais; ao temperamento e qualidades morais; às capacidades ou à aptidão para imagens verbais; à espontaneidade e timidez; à idade mental, bem como ao respectivo coeficiente de inteligência; à atividade psicomotora em geral; à capacidade de crítica e de invenção lógica; à competência para combinar, permutar e deduzir; ao nível cultural e de desenvolvimento escolar; às capacidades adquiridas de leitura e cálculo; à capacidade de adaptação a novas circunstâncias; ao estado da higiene mental e corporal; às vocações profissionais, dentre elas, a aptidão militar; à tendência ao vício e ao crime. Enfim, tratava-se da investigação técnica do material humano com vistas a detectar anormalidades e impedir que pessoas inadaptadas assumissem posições sociais pouco condizentes com seu status biológico.

Na mesma linha, A escola e a psychologia experimental, obra assinada por Edouard Claparède (1928), permite-nos secretar as estratégias científicas que abordavam um aspecto bastante amplo do comportamento: o interesse. Já no prefácio, o tradutor Lourenço Filho aponta-nos que a leitura de Claparède (1928, p. 7) permitiu a ele especular que "[...] a creança não deve trabalhar ou conduzir-se bem pela coação do mestre ou dos paes, mas porque se desperta nella um 'interesse' real e profundo [...]". Institui-se, dessa forma, a "escola sob medida" (CLAPARÈDE, 1928, p. 8), dedicada a aplicar técnicas capazes de estabelecer, reconhecer e conduzir o interesse dos educandos. 
Para tanto, Claparède (1928, p. 14) sobreleva a necessidade de conhecer profundamente o desenvolvimento mental dos pupilos, pois "[...] não se governa a natureza sinão prestando-lhe obediência [...]". Entre os fundamentos naturais da criança, Claparède encontra o jogo como ação inata do homem, pois, “[...] ao collocar o amor ao jogo ou a tendencia do jogo, na alma da creança, a natureza a armou admiravelmente contra sua própria incapacidade de interessar-se pelas realidades da vida [...]" (ibidem, p. 19).

O interesse, portanto, não é uma condição prévia da natureza infantil; ele seria instalado, segundo Claparède, pela ação educativa e, nela, o estímulo ao jogo seria a técnica mais adequada. A partir daí, o autor passa a explorar a construção de pontes entre desejo e ação.

Tais pontes seriam arquitetadas por técnicas de estímulo da memória; nesse caso, o educador deveria estar atento à fidelidade dos testemunhos para garantir exercícios mnemônicos confiáveis. A veracidade e a coerência dos testemunhos dependeriam, segundo Claparède (1928), de uma gama de processos mentais, dentre outros: acuidade visual; deslocamento dos olhos no correr da leitura; percepção da palavra; linguagem interior; compreensão de frases e ideias. Todos esses processos deveriam ser investigados por testes que definiriam as aptidões naturais de tal ou qual indivíduo, este tomado isoladamente ou no interior dos tipos mentais em que cada qual pudesse ser alocado. Depois de serem definidas as aptidões e descobertos os tipos mentais, o educador poderia dirigir suas preocupações para fatores diversos, tais como: energia mental (indivíduo diurno ou noturno); resistência à fadiga; alterações patológicas nas emoções; cultura mental "[...] na acquisição de certos habitos de espirito [...]" (CLAPARÈDE, 1928, p. 83); personalidade do professor etc.

Para Claparède (1928, p. 62), uma educação bem sucedida seria aquela que respeitasse a natureza da criança e, por conseguinte, auxiliasse no seu pleno desenvolvimento em direção à fase adulta. $\mathrm{O}$ autor considera que "[...] o adulto raciocina, emquanto que a criança tactea, ensaia até que realise ou descubra o que deseja [...]". Ou seja, o comportamento adulto seria o ponto culminante de um processo de amadurecimento que partiria do respeito à natureza do infante e que demandaria a condução científica da índole jogadora até chegar ao adulto interessado. De acordo com essa concepção, a educação seria um processo por meio do qual o desejo da criança é codificado segundo critérios verificáveis de desempenho. Concomitantemente, sua vontade de jogar seria conduzida àquilo que os codificadores consideram realidades da vida. 
No processo de codificação do desejo infantil para guindá-lo ao interesse adulto, ganha destaque a educação moral. No volume da Bibliotheca de educação, sob o título de Educação moral e educação econômica, Sampaio Doria (1928, p. 29), reformador paulista, enuncia que "[...] a educação moral é, em substancia, educação da vontade [...]". A vontade, segundo o autor, é aquilo que torna os homens entes de ação, subordinados às forças impulsivas das emoções, suscetíveis aos instintos e avessos ao "[...] raciocínio frio [...]" (ibidem, p. 35). Desse modo, educar a vontade, instituindo ações morais, significaria submetê-la à máxima: “[...] o hábito do bem e o horror do mal [...]" (ibidem, p. 17).

Tal educação da vontade, segundo Sampaio Doria (1928), deveria garantir três âmbitos: a liberdade, a consciência e a responsabilidade. O ser livre surgiria na medida em que "[...] o individuo só é alguém, quando se firmar o hábito de resolver-se por si mesmo [...] no ideal do homem consciente, se suppõe experiencia, cultura e equilibrio mental [...]" (DORIA, 1928, p. 17-18). Por fim, o responsável seria aquele capaz de "[...] receber as consequencias de seus actos ou omissões [...]" (ibidem, p. 19). Tal responsabilidade também estaria associada à necessidade de conservação da vida, condição "[...] necessária á conservação normal da natureza humana [...]” (ibidem, p. 45). Assim, na linha de Durkheim (1929), a mesma reação que o corpo natural tem a agressões exteriores (tais como as provocadas pelo abuso do álcool, por exemplo), o corpo social a teria por meio de suas leis e punições.

A escola moral, na visão do autor, seria aquela que, por meio da inoculação de hábitos nos discentes, torná-los-ia autônomos, equilibrados e consequentes. Tais ações estariam em consonância com a compreensão do educando como "[...] entidade bio-psychica [...]" (DORIA, 1928, p.7); uma entidade que observasse o princípio de que a obediência social faz parte da natureza humana.

Sobre o substrato da vontade, Sampaio Doria (1928) ergue o edifício moral por via da educação e demonstra como o ato de educar torna o homem um ser social, isto é, naturalmente livre para reconhecer o bem e obedecer aos codificadores desse bem. Porém, a natureza narrada por Sampaio Doria não seria igual para todos; há aqueles que suportam melhor as indicações morais e há aqueles que as questionam, cada qual agindo segundo seu tipo pessoal.

Para definir esse tipo, a lógica discursiva cara ao escolanovismo recorria aos exames. Ao fazê-lo, produziam-se classificações que, entre outras ações, inseriam as idiossincrasias em biotipos. Atenhamo-nos a um conceituado biotipologista potiguar: Peregrino Junior. 
Endocrinologista e professor de medicina, viveu entre 1898 e 1983, e atuou em diversos cargos da administração federal no Rio de Janeiro, tendo sido fundador da Sociedade Brasileira de Endocrinologia, Biotipologia e Nutrição. Seu nome é citado com frequência pelos autores presentes na Bibliotheca de educação. O texto em análise foi extraído do livro Biotypologia e educação (1936). Trata-se de um documento publicado pela Diretoria Nacional de Saúde e Assistência Médico-Social, no qual o autor condensou uma sequência de palestras apresentadas a professores primários em 1935.

Nele, encontramos uma cena de antropometria digna de destaque: a relação tronco-membros. Esta define-se como

[...] a differença algebrica entre o valor do tronco e o valor dos membros. É a mais importante das relações fundamentaes. É a relação basal, a primeira adoptada por Viola e a única que era tomada em consideração durante muito tempo. Morphologicamente ella analysa as proporções entre o volume do tronco e o desenvolvimento tentacular dos membros. Funccionalmente representa a relação entre o systema da vida vegetativa (tronco) e o systema da vida de relação (membros) [...] (PEREGRINO JUNIOR, 1936, p. 72).

Para que fosse possível estabelecer a relação tronco-membros, dever-se-ia dividir o primeiro em cinco segmentos, antes de medir outras cinco frações dos membros. A primeira medida, tronco-vertical, dá conta da distância entre a região jugular e o último terço do esterno; a segunda afere a distância entre o esterno e a região epigástrica, acima do umbigo; a terceira dista do epigástrico ao púbis; a quarta mede o tronco superior, sem as mãos. Com a exclusão do pé, mede-se o tronco inferior-vertical: quinta medida. Há outras cinco medidas para os membros em sua horizontalidade.

As relações fundamentais referem-se aos números a partir dos quais se desdobram todas as outras medidas passíveis de comparação, quer no volume, quer no comprimento dos corpos investigados. Por meio da dita proporção entre membros e tronco, poder-se-ia distinguir os indivíduos longilíneos dos brevilíneos. Nos segundos, predominariam as funções vegetativas, tais como a nutrição e a reprodução; já nos alongados, em virtude da extensão dos membros, prevaleceriam as funções de relação.

A imagem é clara: os longilíneos, por possuírem membros maiores, possuíam mais superfície de contato com o mundo, tendendo, portanto, a ser mais habilidosos no que se refere às relações sociais. Tal tendência 
traria consigo o risco de predominarem os instintos agressivos. No caso dos brevilíneos, o maior volume no tronco condicionaria tais indivíduos a maior recolhimento. Ao se ensimesmarem, os brevilíneos ficariam expostos ao risco de desenvolverem comportamentos próprios dos deprimidos.

A partir da relação entre constituição e comportamento, Peregrino Júnior (1936) preocupa-se em dimensionar as reações dos diferentes tipos constitucionais perante adversidades, tais como doenças. Por exemplo: o tipo brevilíneo, quando adoece, “[...] não tendo o ventre, o sexo e os músculos em ordem, elles não comprehendem a vida, porque é disso que depende a sua felicidade e o seu equilíbrio [...]" (PEREGRINO JUNIOR, 1936, p. 50). Já os longilíneos reagem desacreditando a doença, desprezando-a.

Todas as reações adversas, danosas sob o ponto de vista da salubridade ou da sociabilidade, poderiam ser antecipadas e evitadas, caso tanto os professores quanto demais condutores das crianças conhecessem a ciência dos tipos morfológicos e se preparassem para evitar ou corrigir o predomínio da tendência natural sobre o bem agir.

Acerca das tendências naturais, também disserta Henrique Geenen. Autor do quarto volume da Bibliotheca de educação, foi apresentado por Franco da Rocha (1929, p. 263) como um “[...] professor há muitos annos e um apaixonado da psycologia [...]”. É dele também um Compendio de filosofia, publicado em 1933.

Geenen, assim como seus companheiros de Bibliotheca, preocupou-se com o jogo explicativo entre constituição fisiológica e comportamento. Conforme suas teorizações, seria necessário distinguir dois campos de observação dos humanos: o hereditário e o adquirido. O conceito de temperamento seria empregado para compreender ações motivadas pelos instintos (constitucionais, hereditários). Por outro lado, o termo caráter definiria o comportamento resultante da interferência do hábito sobre a base genética. Por meio da ação rotineira e moralmente regulada sobre a base fisiológica, formar-se-ia o caráter. Este aponta para a dimensão humana que mais explicitamente se relaciona com a educação.

Para fundamentar suas concepções, o autor recorre a um roteiro que inclui teorizações de diferentes campos científicos relativas ao sistema nervoso, à hereditariedade, às secreções endócrinas, à psicanálise, à paleontologia, à frenologia e à antropologia. Quanto à infância, Geenen (1929) discorre: 
[...] o indivíduo humano, nos primeiros mezes de sua vida, quando é criança de peito e que nelle preponderam os sentidos inferiores, a vida surda dos impulsos e dos reflexos, acha-se no estado de mammifero. Na segunda metade do primeiro anno, com a actividade de apanhar e de imitar tudo, alcança o estado dos macacos anthropoides superiores. No segundo anno, por meio do andar erecto e da linguagem, chega ao estado do homem propriamente dito. Nos cinco annos seguintes, na idade dos brinquedos, dos contos phantasticos, acha-se no estado dos homens primitivos. Se em seguida, pela frequencia da escola, vem a incorporação ao meio social com os deveres rigorosos, a distinção entre ociosidade e trabalho [...] (GEENEN, 1929, p. 73).

Ao analisar o desenvolvimento da criança em direção à vida adulta, Geenen vislumbra toda a história da evolução das espécies e, no interior dela, das sociedades humanas, em direção à civilização. Ontogênese e filogênese irmanadas, pois.

O neonato seria refém de seus "sentidos inferiores" e relacionar-se-ia com o mundo exterior por meio dos "impulsos e reflexos". A partir dessa ideia, Geenen demonstra que, nessa fase, é possível descrever, a partir das formas anatômicas do crânio (tal como a paleontologia faz com os primitivos), as capacidades em germe para os próximos momentos da vida. Na primeira infância, portanto, localizar-se-ia o momento privilegiado para conhecer os instintos humanos herdados (não apenas pela via familiar, mas, de certa forma, por toda a espécie). Tais instintos perpetuar-se-iam vida afora por meio daquilo que o autor chama de temperamentos. Estes representariam o substrato constitucional do ser. Haveria a possibilidade, inclusive, de discriminar diferentes tendências consoantes aos temperamentos: paranoica, perversa, mitomaniaca, ciclotímica e hiperemotiva.

Na segunda fase da infância, segundo Geenen, despontaria a disposição à imitação. Essa característica, compartilhada com os macacos antropoides, predisporia o indivíduo à interação social. Nesse processo, o confronto com os pais e com a sociedade levaria a conflitos internos cujo encaminhamento íntimo resultaria na composição de complexos e mecanismos de sublimação e recalcamento. Geenen afirma que esse estágio do desenvolvimento humano justifica a atuação da psicanálise nas idades posteriores, com o objetivo de colocar em palavras os conflitos íntimos, sempre no sentido de saná-los.

Entretanto, a lógica discursiva evocada por Geenen não conviveria com indivíduos inusitados. Arma-se sobre eles, dessa forma, aquilo que garantiria o viés definidor, generalizante e interventivo da ciência dos caracteres: a classificação. Dentre as classificações apresentadas pelo autor, destacamos 
a de Boll e Delmas. Estes definiram oito elementos constitutivos do caráter (emotividade, avidez, bondade, sociabilidade, atividade, imaginação, memória e juízo), cada um deles graduável em sete níveis. Dessa forma, Boll e Delmas chegam a 5.764.801 grupos diferentes de caracteres (oito elementos elevados à sétima potência, esta representativa dos graus em que cada um dos elementos se apresenta). Por exemplo, Boll e Delmas afirmariam que:

[...] o typo 'intrigante' é assim representado: $\mathrm{E}=0 ; \mathrm{V}=+2 ; \mathrm{B}=+1 ; \mathrm{S}=+3 ; \mathrm{A}=+1$. Fórmula que devemos ler: no intrigante $\mathrm{E}$, a emotividade é nulla; $\mathrm{V}$ a avidez é positiva, forte; B, a bondade é negativa, grau fraco; S, a sociabilidade é extrema. A, a actividade, é positiva, grau fraco [...] (apud GEENEN, 1929, p. 60).

Dessa maneira, o inusitado tornar-se-ia dizível e, por meio da linguagem científica, o individual seria definitivamente inserido numa série observável.

Ao definir os aspectos constitutivos (temperamento) e idiossincráticos (caráter) dos indivíduos, Geenen chega a uma conclusão inconteste: considerando a plasticidade da infância, a educação deveria ser orientada para criar hábitos saudáveis e moralmente edificantes para uma boa condução das tendências genéticas, sempre com vistas à produção de adultos equilibrados e produtivos.

Cabe ressaltar, ainda, que tal missão educativa somente poderia ser levada a cabo com a adesão do educando à linguagem comum a todos esses saberes da intimidade. Destarte, poderia então o indivíduo, convencido de sua interioridade cientificamente codificada, identificar-se com seus convivas e com a imagem de humano aí projetada a partir dos critérios oferecidos pelos saberes que vinculam sua individualidade à longa história da criação, da evolução e do desenvolvimento humanos.

O vínculo do indivíduo com sua própria espécie e, por conseguinte, com a história da origem das espécies é consenso entre os autores até aqui elencados. Tal vinculação faz-nos especular sobre a potência performativa dos enunciados da genética no que diz respeito à criação de bioidentidades.

$\mathrm{Na}$ Bibliotheca de educação, há diversos autores que versam sobre temas caros à genética; por exemplo, a obra de Octavio Domingues, constantemente citada por outros autores: A hereditariedade em face da educação (1929).

Domingues, desde a década de 1920 até a de 1960, atuou fortemente no campo da zootecnia. Nesse campo, foi professor e pesquisador com grande volume de obras publicadas. Do mesmo modo, participou ativamente do 
movimento eugênico, tendo pertencido à Sociedade Eugênica de São Paulo, criada em 1918 e operante até a década de 1940.

No último parágrafo do seu $A$ hereditariedade em face da educação, Domingues dirige-se diretamente aos professores:

The creature is not mare, but born - deve ser a sua lembrança constante de cada dia, pois que a individualidade da criança é uma coisa hereditária, é um conjunto de virtualidades innatas, que o mestre de hoje deverá saber conduzir e orientar apenas, sem transmuda-las, como aquelles ingenuos alchimistas que buscam fazer ouro ao toque da pedra filosofal [...] (DOMINGUES, 1929, p. 158).

Traduziríamos a primeira passagem como: “[...] a criatura não é maléfica, mas é gerada [...]". Em bom português: uma criatura, em si, não é necessariamente uma coisa nem outra, mas deve-se ter sempre em mente que todos são fruto de criação. Seja sob controle de um geneticista, seja por cruzamento aleatório, é inegável, segundo Domingues (1929), que se pode prever ou, ao menos, calcular as probabilidades de tal ou qual formação congênita. Independentemente da espécie que se investigue, sempre será possível produzir suposições seguras acerca dos descendentes.

Domingues considera que os homens - sejam eles pessoas comuns, professores ou cuidadores em geral - precisariam conhecer a imensa produtividade da ciência da hereditariedade. Dessa forma, todos, com destaque para os professores, poderiam se valer da genética como fundamento para acessar o mais íntimo de seus alunos: suas tendências.

A tendência, na genética de Domingues, evoca uma libertação em relação ao tempo; ele se torna infinito. Quando um laboratorista detectasse alguma predisposição em determinado indivíduo, ele garantiria a todos os humanos pertencentes à população do examinado a possibilidade de compartilharem com seu parente a ventura ou, em casos de anomalias ${ }^{2}$, o risco mediante uma formação previamente conhecida. O eugenista assevera que o material genético, notadamente no caso de genes heterozigotos, guarda toda a história da evolução humana, todas as suas taras e todos os seus progressos.

2 Domingues possui uma clara ideia de anormalidade: ela define inadequações dos corpos diante de determinados ambientes ou de determinados usos do corpo. É aquilo que Canguilhem (2006) chamaria de patológico. 
Há também o problema da degenerescência. Nesse caso, Domingues (1933) refere-se à “[...] seleção regressiva [...]”. Para tanto, vale-se de estudos de cientistas da Universidade de Yale e da American Psychiatric Association. Estes demonstraram que na população americana havia uma tendência à proliferação dos mais fracos diante dos geneticamente superiores. Os dados comprovavam que a alta taxa de natalidade era uma das características intrínsecas às comunidades em que abundavam seres degenerados. Expandiamse, assim, as formações inadequadas. A culpa disso, Domingues e seus interlocutores atribuem à filantropia. $\mathrm{O}$ autor chega a perguntar e a responder: "[...] que tem feito a ciencia em materia de higiene e medicina? Salvar da morte uma multidão de individuos a ela condenados, sem a sua intervenção providencial [...]" (DOMINGUES, 1933, p. 34).

A genética de Domingues não guarda nenhuma promessa; sua eugenia não é segregacionista. Ele não compactua com as esperanças dos higienistas. Em sua opinião, a educação não tem o mesmo papel redentor que a maioria de seus colegas de Bibliotheca. Um amplo sistema educativo somente teria importância na medida em que todos os envolvidos considerassem os benefícios das investigações genéticas antes dos "cruzamentos". Em plena década do reformismo educacional na qual se forma a Escola Nova, o geneticista - ponta de lança do conhecimento científico - atribui à educação pública um caráter de mera caridade.

Criar um homem consciente dos riscos oferecidos pela hereditariedade: essa deveria ser a meta da educação, no entender do eminente eugenista.

Na mesma chave interpretativa, encontramos Adolphe Ferrière, professor da Universidade de Genebra, na década de 1920, e um dos abnegados promotores da Escola Nova na Europa. Dono de uma abundante obra pedagógica, Ferrière teve seu texto A lei biogenética e a escola activa publicado no nono volume da Bibliotheca, em 1929. O parágrafo a seguir bem poderia sintetizar todos os enunciados tratados até o momento em nosso estudo.

Educação é a arte de iniciar na criança, mediante a excitação do seu interesse, um desenvolvimento das forças intellectuaes e moraes que corresponda ás leis, em virtude das quaes se realiza todo progresso biologico e psychologico, differenciação e correspondente concentração das suas sãs faculdades e energias volitivas [...] (FERRIÈRE, 1929, p. 27). 
Vontade, desenvolvimento, interesse, progresso, moralidade, constituição biológica e estrutura psicológica compõem a longa lista das faculdades para as quais se destinava boa parte dos dizeres da psicopedagogia moderna. Em consonância com os princípios da modernidade escolar, a obra de Ferrière (1929) acrescenta um aspecto fundamental: a liberdade.

"Os meninos, como os cantores do ar, necessitam de amplo espaço ilimitado, para que possam desenvolver e chegar a ser homens fortes serenos e úteis [...]" (FERRIÈRE, 1929, p. 12). Entre as leis da natureza humana aventadas por Ferrière, o impulso à liberdade é a mais cara. $\mathrm{O}$ infante, segundo $\mathrm{o}$ autor, precisa ter garantido seu movimento bem como o contato com a luminosidade e com seus colegas numa viva e imediata troca de experiências intelectuais. O ensino deveria, assim, ser implementado de dentro para fora. Os educadores deveriam dar vazão à capacidade produtiva própria de todo humano. Para tanto, a escola para Ferrière deveria ser ativa, pois deveria basear-se no trabalho. As aulas seriam ministradas em ambiente rural. Os conhecimentos de história, geografia etc. "[...] têm valor somente quando contribuam para a formação integral do homem, e, se o não conseguirem, o seu estudo é um tormento inútil e cruel que impomos às crianças [...]" (FERRIÈRE, 1929, p. 17).

Nessa escola, o erro deveria ser encarado como inadequação do conteúdo cobrado em relação ao "[...] progresso da intelligencia do menino [...]" (FERRIÈRE, 1929, p. 44). Dessa maneira, o trabalho ensinaria e, ao mesmo tempo, permitiria que surgisse o conhecimento espontaneamente, por meio da observação natural da vida humana.

$\mathrm{Na}$ escola proposta por Ferrière (1929), a composição da liberdade com o ensino deveria respeitar uma única verdade: as leis biogenéticas do desenvolvimento humano. Assim, o método do pedagogo constituir-se-ia no jogo entre aquilo que é oferecido pelos professores e o que os alunos são capazes de realizar. A partir da relação dialética interesse-trabalho, Ferrière classifica os diferentes graus do desenvolvimento de seus educandos, quais sejam: 1) idade dos interesses imediatos (6 a 9 anos); 2) idade dos interesses concretos especiais (10 a 12 anos); 3) idade dos interesses abstratos (13 a 14 anos). Destarte, os discentes em liberdade deveriam ser submetidos a um conjunto de estímulos cuja exigência seria determinada pela capacidade de execução dos colegas que os precederam e, concomitantemente, pela habilidade dos educadores em criar codificações para essas capacidades. 


\section{Nunca fomos tão modernos - à guisa de conclusão}

Um ser geneticamente programado para ser livre. Um aluno passível de avaliação. Uma criança desejosa de brincar. Um estudante apto à moralização. Um humano com temperamento reconhecível. Um infante suscetível à profilaxia psicanalítica. Uma vida descrita por meio de processos bioquímicos.

Ao discorrerem sobre suas concepções acerca de métodos educativos desejáveis, os oito autores acima retomados parecem percorrer, em alguma medida, toda a história da ciência na modernidade. Nossos autores vislumbraram um homem em desenvolvimento, cujas ações seriam previsíveis porque verificáveis por métodos que partem da coleta de dados, transitam pela apreciação matemática e chegam a generalizações para um humano em geral.

No entanto, há distensões patentes: o eugenista não tem fé na educação; o moralista busca inserir responsabilidade onde existe a liberdade, esta sendo constitucional para o psicogeneticista; a vontade do jogo, percebida pelo psicólogo, poderia ser relativizada pelo caráter; o biotipologista, por fim, atrela imediatamente fisiologia e comportamento, mas minimiza a atuação do inconsciente freudiano. Contudo, todos eles coabitam na Bibliotheca de Lourenço Filho.

O que os amalgama, em nosso entendimento, são seus esforços em direção à edificação de bioidentidades. Ao discorrerem sobre uma natureza infantil, cientificamente descritível e psicologicamente manipulável, os pedagogos modernos submetem o objeto de seus estudos a um quadro identitário inequívoco e, salvo melhor juízo, irredutível.

Ontem, assim como hoje, no intercâmbio da pedagogia com a psicologia, a filosofia, a sociologia, a estatística, a pediatria e a psiquiatria, entre outros saberes, parece residir a codificação da ampla gama de possibilidades de capturar em palavras as atitudes dos educandos. Mais do que captura, a codificação das idiossincrasias parece operar por meio da definição de critérios bioidentitários a partir dos quais cada qual devesse reconhecer a si mesmo.

Ao aventar a psique como instância em que as diferentes tendências humanas manifestam-se e definem as especificidades individuais, os cientistas do comportamento arrogam-se a responsabilidade de levar a cabo previsões e, por conseguinte, manipulações dos mecanismos que regem as atitudes daqueles sob sua guarda examinatória. Dessa maneira, criam critérios de avaliação e instigam cada qual dos avaliados a justificar suas capacidades à luz dos resultados dos testes que eles próprios, os experts - e, em sentido estendido, a comunidade cientifica - definiram como normais. 
Aproximando-nos de Friedrich Nietzsche (2009), não nos furtamos a reputar tal expediente como fundado em arbitrariedades. Homens da ciência constituindo argumentos carregados de sentidos contingentes esboçam uma natureza para o que denominam humano e ancoram suas generalizações em assertivas morais. Para eles, o sujeito normal é também o cidadão moral.

No interior da norma produzida pelas sondagens estatísticas, as verdades ganham estatuto de essência humana. Daí que o homem que a elas não subscrevesse estaria insurgindo-se contra a marcha pessoal e humanitária em direção ao progresso. Concordamos, assim, com Georges Canguilhem (2006, p. 44), para quem "[...] uma norma não existe, apenas desempenha seu papel que é de desvalorizar a existência para permitir a correção da mesma existência [...]".

Responsabilização, manipulação, imposição: nenhum desses termos é exato o bastante para designar os efeitos de saber-poder gerados nos e pelos discursos dos pedagogos modernos, seja na década de 1920, seja no século XXI. A palavra-chave desse discurso é, não obstante, uma e apenas uma: autonomia. Uma autonomia densamente regulada, posto que os sujeitos tornados objeto das ciências que os definem a priori deveriam assumir livremente as possibilidades sanativas das práticas científicas que os circunscrevem.

Por meio do enfrentamento com nossas fontes, torna-se patente que, fosse na investigação do biotipo, fosse na detecção do temperamento, fosse ainda na perspectiva hereditária, moralista ou libertária, todos os avaliados deveriam mostrar sua boa vontade com relação aos seus abnegados investigadores, pois que estes postavam-se como especialistas capazes de apontar os meios mais seguros para encaminhar, restaurar e prevenir atitudes inadequadas.

Acreditamos visualizar nesse tipo implacável de condução das condutas o motivo pelo qual a infância foi o momento preponderante para os estudiosos da psique e, em especial, aquela do alunado. Além de os educandos constituírem um grupo social cativo para as sondagens, também eles estavam à mercê do entourage escolar para a inoculação de determinados hábitos edificantes, os quais deveriam ser incorporados às individualidades como atos da vontade.

Evidentemente, uma forte motivação para o confinamento escolar nas cidades industriais sempre se atrelou à necessidade de retirar as crianças dos espaços públicos e garantir-lhes alguma formação profissional. No entanto, nunca essa prioridade ficou desacompanhada das pretensões civilizatórias e, por conseguinte, ilesa à maquinaria subjetivadora típica das práticas educativas.

Ao visitarmos os primeiros tempos da pedagogia científica no Brasil, pelas mãos de alguns autores da Bibliotheca de educação, deparamo-nos com 
uma complexa e inquebrantável conexão empírica entre natureza, infância e ciência. Tal conexão garantiu contatos indeléveis entre certas concepções de humanidade, desenvolvimento corpóreo e previsão de condutas, no seio dos discursos escolares.

A pedagogia atual, quase consensualmente, distancia-se da frenologia, da biotipologia, da eugenia, do inatismo, do racismo, do higienismo e do darwinismo social; contudo, parece manter-se intacto algo do modus operandi dos biotipologistas, experimentalistas, eugenistas e higienistas de outrora. Tal modus reatualiza-se em discursos psicodesenvolvimentistas, neurocientíficos, libertários, autonomistas, responsabilizadores - todos eles promotores de uma escola centrada menos na capacitação do alunado, e mais no exercício incansável de sua normalização.

Tudo isso foi e continua possível, a nosso ver, graças à manutenção da pregressa conexão entre fisiologia e conduta, ao projetarmos, palmo a palmo, crianças naturalmente classificáveis; crianças-receptáculos de corpos e almas escancarados à inoculação científica de critérios de veridicção e ajuizamento de suas existências.

\section{Fontes}

ClaParède, Edouard. A escola e a psychologia experimental. São Paulo: Companhia Melhoramentos de S. Paulo, 1928 (Coleção Bibliotheca de educação, v. 2).

Domingues, Octavio. A hereditariedade em face da educação. São Paulo: Companhia Melhoramentos de S. Paulo, 1929 (Coleção Bibliotheca de educação, v. 6).

. Eugenia: seus propósitos, suas bases, seus meios. São Paulo: Companhia Editora Nacional, 1933.

Doria, Antonio de Sampaio. Educação moral e educação economica. São Paulo: Companhia Melhoramentos de S. Paulo, 1928 (Coleção Bibliotheca de educação, v. 3).

Durkheım, Émile. Educação e sociologia. São Paulo: Companhia Melhoramentos de S. Paulo, 1929 (Coleção Bibliotheca de educação, v. 5). 
Ferrière, Adolpho. A lei biogenética e a escola activa. São Paulo: Companhia Melhoramentos de S. Paulo, 1929 (Coleção Bibliotheca de educação, v. 9).

Geenen, Henrique. Temperamento e carácter sob o ponto de vista educativo. São Paulo: Companhia Melhoramentos de S. Paulo, 1929 (Coleção Bibliotheca de educação, v. 4).

Peregrino Junior. Biotypologia e educação. Rio de Janeiro: Diretoria Nacional de Saude e Assistencia Medico-social Secção de Informação, Propaganda e Educação Sanitária, 1936 (Coleção IPES, n. 2).

PIÉron, Henri. Psychologia experimental. São Paulo: Companhia Melhoramentos de S. Paulo, 1927 (Coleção Bibliotheca de educação, v. 1).

\section{Referências}

Benczik, Edyleine Bellini Peroni. Transtorno do déficit de atenção/hiperatividade: um guia de orientação para profissionais. São Paulo: Casa do Psicólogo, 2000.

Canguilhem, Georges. O Normal e o patológico. Rio de Janeiro: Forense Universitária, 2006.

CAstel, Robert. A gestão dos riscos: da anti-psiquiatria à pós-psicanálise. Rio de Janeiro: Francisco Alves, 1987.

D’Avila, Jerry. Diploma de brancura: política social e racial no Brasil - 19171945. São Paulo: Editora UNESP, 2006.

- Sobre as maneiras de escrever a história. In: . Arqueologia das ciências e história dos sistemas de pensamento. Rio de Janeiro: Forense Universitária, 2000. p. 62-77. (Ditos e escritos, n. 2).

. O governo de si e dos outros: curso no college de France (1982-1983). São Paulo: WMF Martins Fontes, 2010.

Gondra, José Gonçalves. A sementeira do porvir: higiene e infância no século XIX. Educação e Pesquisa, São Paulo, v. 26, n. 1, p. 99-117, jan./jun. 2000. 
Lima, Rossano Cabral. Somos todos desatentos? O TDA/H e a construção de bioidentidades. Rios de Janeiro: Relume Dumará, 2005.

Lourenço Filho, Manuel Bergström. Introdução aos estudos da escola nova. São Paulo: Melhoramentos, 1963.

Machado, Roberto; Loureiro, Ângela; Luz, Rogério; Muricy, Kátia. Da(n)ação da norma: medicina social e constituição da psiquiatria no Brasil. Rio de Janeiro: Graal, 1978.

Mattos, Paulo. No mundo da lua: perguntas e respostas sobre o transtorno do déficit de atenção em crianças, adolescentes e adultos. São Paulo: Lemos Editorial, 2001.

Mate, Cecília Hanna. Tempos modernos na escola: os anos 30 e a racionalidade da educação brasileira. Bauru: EdUSC; Brasília: INEP, 2002.

Monarcha, Carlos. Lourenço Filho e a Bibliotheca de educação (1927-1941). In: . (Org.). Lourenço Filho: outros aspectos, mesma obra. Campinas: Mercado de Letras - UNESP, campus Marília, 1997. p. 27-57

Nietzsche, Friedrich Wilhelm. Genealogia da moral: uma polêmica. São Paulo: Companhia das Letras, 2009.

Ó, Jorge Ramos do; Carvalho, Luiz Miguel. Emergência e circulação do conhecimento psicopedagógico moderno (1880 - 1960): estudos comparados Portugal e Brasil. Lisboa: Educa, 2009.

PAtTo, Maria Helena Souza. Psicologia e ideologia: uma crítica à psicologia escolar. São Paulo: T.A Queirós, 1984.

. A produção do fracasso escolar: histórias de submissão e rebeldia. São Paulo: Casa do psicólogo, 1999.

Rabinow, Paul. Antropologia da razão. Rio de Janeiro: Relume Dumará, 2002.

Rohde, Luís Augusto, et al. Princípios e práticas em transtorno de déficit de atenção/hiperatividade. Porto Alegre: Artmed, 2003.

Rose, Nikolas. Inventando nossos eus. In: Silva, T. T. (Org.). Nunca fomos humanos. Belo Horizonte: Autêntica, 2001. p. 137-178.

. Neurochemical selves. Society, Londres, p. 46-59, nov./dec. 2003. 
Sevcenko, Nicolau. Orfeu extático na metrópole: São Paulo e os frementes anos 20. São Paulo: Companhia das Letras, 1992.

Silva, Ana Beatriz Barbosa. Mentes inquietas: compreendendo melhor o mundo das pessoas distraídas, impulsivas e hiperativas. São Paulo: Gente, 2003.

Veyne, Paul Marie. Como se escreve a história: Foucault revoluciona a história. Brasília: Editora Universidade de Brasília, 1982.

- Acreditavam os gregos em seus mitos? Ensaio sobre a imaginação constituinte. São Paulo: Brasiliense, 1984.

Endereço para correspondência:

Marcelo Rito

Rua Manuel Cherem, 300, ap. 65-A

Vila Paulista

São Paulo - SP

CEP: 04360-030

E-mail: marcelorito@usp.br

Julio Groppa Aquino Faculdade de Educação/ Universidade de São Paulo Av. da Universidade, 308, $2^{\circ}$ andar

Cidade Universitária São Paulo - SP CEP: 05508-040 E-mail: groppaq@usp.br

Recebido em: 27 mar. 2012 Aprovado em: 12 jun. 2012 